\title{
Transfer Pragmatik dalam Keluhan pada Mahasiswa Asing Pembelajar Bahasa Indonesia di UGM
}

\author{
Riza Nuzulul Huda' ${ }^{\mathbf{1}}$ B. R. Suryo Baskoro ${ }^{2}$ \\ ${ }^{1}$ Universitas Gadjah Mada, Yogyakarta, Indonesia \\ ${ }^{2}$ Associate Professor in Linguistics at Universitas Gadjah Mada, Yogyakarta, Indonesia
}

\begin{tabular}{l}
\hline Article Info \\
\hline Article history: \\
Submitted Jan 25, 2020 \\
Revised Feb 19, 2020 \\
Accepted March 26, 2020 \\
Published April 30, 2020
\end{tabular}

Keywords:

Complaint

Speech Act

Second Language Acquisition

Pragmatic Transfer

Sociolinguistics

\section{Kata Kunci:}

Keluhan

Tindak Tutur

Pemerolehan Bahasa Kedua

Transfer Pragmatik

Sosiolinguistik

\begin{abstract}
In the language competence that is inseparable from the speech act strategies, the socio-pragmatic transfer ability of second language learners can be explored in the use of speech acts which were currently examined through the use of complaints. This study aimed to describe what are the differences of speech act strategies in complaints used in English and Indonesian by International students and how pragmatic transfers in complaints are used by foreign students in producing languages. The data collection used Discourse Completion Test (DCT) with 4 International students in Fakultas Ilmu Budaya Universitas Gadjah Mada who stayed less than 6 months in Indonesia. The threat strategies were generally used to the hearer who have lower social status even with intimacy. However, when social status is aligned, the choice of complaint strategies switched to explicit strategies, on the other side, when the status of interlocutors is higher than the speaker, the use of the speech act strategy was replaced by implicit strategies.
\end{abstract}

\begin{abstract}
ABSTRAK
Dalam kompetensi berbahasa yang tidak terlepas dari strategi tindak tutur, kemampuan transfer sosiopragmatik seorang pembelajar bahasa kedua dapat ditelaah dalam menggunakan tindak tutur, yang saat ini dikaji melalui penggunaan keluhan. Beberapa jenis strategi penggunaan keluhan dapat dipengaruhi oleh jarak sosial, status sosial dan sistem norma sosial antara pemberi dan penerima keluhan. Penelitian ini mendeskripsikan apa saja perbedaan strategi tindak tutur dalam keluhan yang digunakan dalam bahasa Inggris dan bahasa Indonesia oleh mahasiswa asing dan bagaimana transfer pragmatik dalam produksi bahasa kedua. Pengumpulan data dalam penelitian ini menggunakan Discourse Completion Test (DCT) dengan responden 4 mahasiswa pembelajar bahasa Indonesia tidak lebih dari 6 bulan tinggal di Indonesia yang menjadi data primer. Secara umum, strategi ancaman dipilih untuk mitra tutur yang mempunyai status sosial lebih rendah walaupun memiliki kedekatan jarak sosial. Namun ketika status sosial sejajar, pemilihan strategi keluhan beralih pada ujaran eksplisit, sebaliknya, ketika status mitra tutur lebih tinggi daripada penutur, penggunaan strategi tindak tutur berganti dengan pernyataan implisit.
\end{abstract}

\section{Corresponding Author:}

Riza Nuzulul Huda,

Magister of Linguistics, Faculty of Cultural Sciences,

Universitas Gadjah Mada

Jl. Sosio Humaniora, Depok, Sleman, Yogyakarta, Indonesia.

Email: riza.nuzulul.huda@mail.ugm.ac.id

\section{PENDAHULUAN}

Dewasa ini, hampir setiap manusia dapat menuturkan lebih dari dua bahasa karena kesemestaan dunia yang semakin lekat dengan kehidupan. Hal tersebut menjadikan setiap manusia mempunyai bahasa ibu dan mempelajari suatu bahasa sebagai bahasa keduanya. 
Ellis (1994, p.11) menjelaskan bahwa bahasa kedua adalah bahasa yang pada umumnya digunakan untuk menyebutkan bahasa selain bahasa ibu dan diperoleh dengan proses pembelajaran. Kemudian, Ellis menekankan pada peran bahasa kedua sebagai peran sosial dalam komunitas yang berfungsi untuk berkomunikasi kepada orang lain yang menuturkan bahasa selain bahasa pertamanya. Penekanan pembelajaran bahasa kedua dan teori pengajaran bahasa saat ini mulai bergeser dari pendekatan gramatikal atau struktural menjadi pendekatan komunikatif (Widowson, 1978; Canale dan Swain, 1980). Hymes (1972, p. 269) pun mencetuskan istilah 'communicative competence' atau kompetensi komunikatif untuk menjelaskan pengetahuan yang harus dimiliki seorang penutur terhadap suatu bahasa agar dapat memproduksi secara kontekstual suatu tuturan yang sesuai dan memahaminya secara komprehensif. Selanjutnya, pemahaman komprehensif dan produksi tuturan komunikatif dalam komunikasi antar budaya ini mendapatkan banyak perhatian untuk dikaji. Beberapa diantaranya menelaah mengenai kajian pragmatik dalam strategi komunikasi antar budaya melalui tindak ilokusi atau dimensi kesantunan dalam suatu tindak tutur (Blum-Kulka dan Kasper, 1993).

Olshtain dan Weinbach (1993) mengungkapkan bahwa suatu tuturan dapat dikatakan menggunakan tindak tutur keluhan jika penutur mengekspresikan ketidaksukaan dan kekesalannya sebagai reaksi atas peristiwa yang sudah berlalu maupun yang masih berlangsung (p.108). Hal ini harus diungkapkan secara verbal atas respon suatu hal yang telah mengecewakan penutur terhadap mitra tuturnya. Di sini, penutur menganggap bahwa kekesalannya tidak terlepas dari tanggung jawab mitra tutur sehingga penutur akan menggunakan tindak tutur untuk mengungkapkan keluhannya. Selain itu, ada lima strategi penggunaan tindak tutur ini untuk pengelompokannya menurut Olshtain dan Weinbach (1993), yaitu implisit, pertidaksetujuan, eksplisit, peringatan dan ancaman.

Beberapa jenis strategi penggunaan keluhan di atas dapat dipengaruhi oleh jarak sosial, status sosial dan pemahaman sistem obligasi antara pemberi keluhan dan penerima keluhan. Saat jarak sosial antara penutur dan mitra tutur rapat, diasumsikan keluhan akan semakin kritis karena faktor kedekatan (intimacy) yang sudah terbangun. Sedangkan status sosial sebagai pertimbangan posisi untuk melakukan keluhan kepada seseorang yang berstatus sosial lainnya juga sangat mempengaruhi penggunaan suatu strategi keluhan tertentu. Ketika masyarakat yang multikultural dalam suatu lingkungan berinteraksi, terdapat beberapa norma dan kaidah yang berbeda sehingga dapat menghasilkan persepsi dalam penggunaan bahasa yang berbeda pula.

Perihal penggunaan tindak tutur yang berlaku pada masyarakat multikultural dan multilingual terdapat banyak faktor yang mempengaruhinya. Terma transfer pragmatik digunakan Kasper dan Blum-Kulka (1993) ketika pengaruh bahasa pertama dan budaya setempat dalam pengetahuan pragmatik dapat mempunyai resiko dalam keberhasilan komunikasi dalam bahasa kedua (p.5). Hal ini dikarenakan pemilihan formula semantik dan token linguistik masih sangat berhubungan dengan bahasa pertamanya. Jika seorang pembelajar bahasa berhasil mencapai penggunaan tuturan melalui pemahaman sosiokultural bahasa target, maka penutur tersebut berhasil melakukan transfer positif. Sebaliknya, ketika penutur bahasa kedua belum berhasil menggunakan tuturan sesuai perspektif pragmatik bahasa target, maka penutur mengalami transfer negatif. 
Penelitian ini berbeda dengan penelitian sebelumnya yakni penelitian Widayanti, S. R. \& Kustinah (2019), Raymonda, A., Djatmika \& Subroto, E. (2016) dan Rohmadi, M. (2019) yang kajiannya mengenai sosio/psiko pragmatik dalam fungsi tindak tutur secara umum maupun secara khusus untuk tindak tutur meminta, sedangkan penelitian ini memfokuskan kajian pada tindak tutur mengeluh, seperti yang pernah diteliti oleh Fatmasari (2015). Pada penelitian Fatmasari yang berjudul "Strategi Komplain dari Pembelajar Bahasa Inggris sebagai Bahasa Asing dalam Perspektif Tugas Penyelesaian Percakapan (Studi Kasus terhadap Mahasiswa Sastra Inggris Universitas Brawijaya)" berfokus terhadap strategi komplain yang digunakan oleh Mahasiswa Sastra Inggris Universitas Brawijaya dengan menggunakan teori dari Trosborg (1995), objek penelitiannya difokuskan pada penutur jati bahasa Indonesia. Dengan objek penelitian tentang keluhan, "A Cross-Cultural Study of Complaint Strategies by Chinese and British University Student" yang ditulis Yang (2016) menelaah bagaimana penutur asli Cina yang belajar bahasa Inggris menggunakan tindak tutur keluhan dalam bahasa Inggris dan apa saja strategi yang mereka gunakan. Selain itu, penelitian Yang juga membandingkan antara norma pembelajar bahasa Inggris dengan norma penutur asli bahasa Inggris. Teori yang digunakan adalah teori kesantunan dari Leech dalam penggunaan tindak tutur keluhan dan teori kerjasama dari Grice dengan empat maksim sebagai patokannya. Sedangkan dalam penelitian ini, penulis mengambil objek penelitian pada pembelajar bahasa kedua dan dilengkapi penjelasan terma transfer pragmatik yang dapat berhasil/tidak untuk diproduksi dalam sebuah tuturan. Selain itu, penulis juga mengkaji permasalahan faktor konteks yang dapat mempengaruhi penggunaan suatu tindak tutur tertentu, khususnya dalam tindak tutur keluhan pada mahasiswa asing pembelajar bahasa Indonesia. Sehingga penelitian ini mencoba memformulasikan jawaban permasalahan yang dirumuskan menjadi apa saja perbedaan strategi tindak tutur dalam keluhan yang digunakan dalam bahasa Inggris dan bahasa Indonesia oleh mahasiswa asing dan bagaimana transfer pragmatik dalam keluhan digunakan oleh mahasiswa asing dalam memproduksi bahasa.

\section{TEORI DAN METODOLOGI}

Subjek dalam penelitian ini adalah 4 pembelajar bahasa Indonesia yang belajar di Fakultas Ilmu Budaya Universitas Gadjah Mada dengan tidak lebih dari 6 bulan tinggal di Indonesia.

Instrumen penelitian ini menggunakan Discourse Completion Test (DCT) yang terdiri dari 16 wacana yang harus dilengkapi dengan tuturan langsung oleh responden. Lebih lanjut, DCT ini terdiri dari 8 wacana pancingan dalam bahasa Inggris yang harus diberi respon bahasa Inggris, sedangkan 8 wacana lainnya menggunakan bahasa Indonesia dan harus direspon dengan bahasa Indonesia. Penulis memberikan acuan wacana seperti digambarkan pada dua situasi di bawah ini,

You live in dormitory and have a roommate. $S /$ he broke the screen of your laptop which s/he borrowed a day before. It is brand new and you have to do your academic tasks at the moment. You say to your roommate 
Tetangga kamar anda berbicara keras di telepon pada malam hari sehingga mengganggu waktu tidur anda. Anda dalam kondisi yang sangat lelah dan besok harus berangkat pagi. Anda akan berkata pada tetangga kamar anda

Untuk memperoleh data yang sesuai, penulis memberi delapan jenis konteks situasi (tiruan situasi natural) yang akan dijadikan landasan bagi responden untuk menyatakan tuturan keluhannya. Kedelapan jenis situasi yang dimaksud adalah sebagai berikut:

1. Merusakkan barang pada situasi 1 akan menggambarkan status pemberi keluhan (penutur) lebih tinggi dari mitra tutur dan memiliki kedekatan,

2. Membuat antrian pada situasi 2 akan menggambarkan status pemberi keluhan (penutur) lebih tinggi dari mitra tutur namun tidak memiliki kedekatan,

3. Kegaduhan dalam ranah publik pada situasi 3 akan menggambarkan status pemberi keluhan (penutur) setara dari mitra tutur dan memiliki kedekatan,

4. Kegaduhan dalam ranah privasi pada situasi 4 akan situasi yang menggambarkan status pemberi keluhan (penutur) setara dari mitra tutur namun tidak memiliki kedekatan,

5. Nilai buruk pada situasi 5 akan menggambarkan status pemberi keluhan (penutur) lebih rendah dari mitra tutur dan memiliki kedekatan,

6. Fasilitas buruk pada situasi 6 menggambarkan status pemberi keluhan (penutur) lebih rendah dari mitra tutur namun tidak memiliki kedekatan,

7. Keterlambatan pada situasi 7 akan menggambarkan pemberi keluhan (penutur) memiliki kedekatan kepada mitra tutur dan terdapat norma sosial yang berbeda antar budaya,

8. Pertanyaan privasi pada situasi 8 akan menggambarkan pemberi keluhan (penutur) tidak memiliki kedekatan kepada mitra tutur dan terdapat norma sosial yang berbeda antar budaya.

\section{HASIL DAN PEMBAHASAN}

Dari ekspresi melengkapi wacana yang menjadi sumber data penelitian ini diperoleh beberapa strategi keluhan yang dipengaruhi juga oleh konteks. Namun sebelum memaparkan ulasan mengenai bentuk strategi yang diproduksi, penulis juga menemukan beberapa pemilihan frasa yang berbeda walaupun dengan strategi yang serupa. Hal ini digambarkan sebagai berikut,

\section{Frasa/leksikal merendah}

Strategi keluhan yang digunakan pada situasi tidak nyaman kepada mitra tutur juga akan mengandung pemilihan frasa/leksikal merendah yang berguna untuk membuat strategi keluhan tertentu lebih lunak jika diucapkan. Dari data yang ditemukan terdapat beberapa contoh seperti yang digambarkan di bawah ini,

Tabel 1. Frasa/leksikal merendah (lexical/phrasal downgraders)

\begin{tabular}{cccc}
\hline No. & Jenis & Bahasa & \\
\hline 1 & Penunjuk kesantunan & Inggris & Please \\
& & Indonesia & Tolong \\
2 & Perangkat konsultatif & Inggris & Would you mind, if it's possible \\
\hline
\end{tabular}




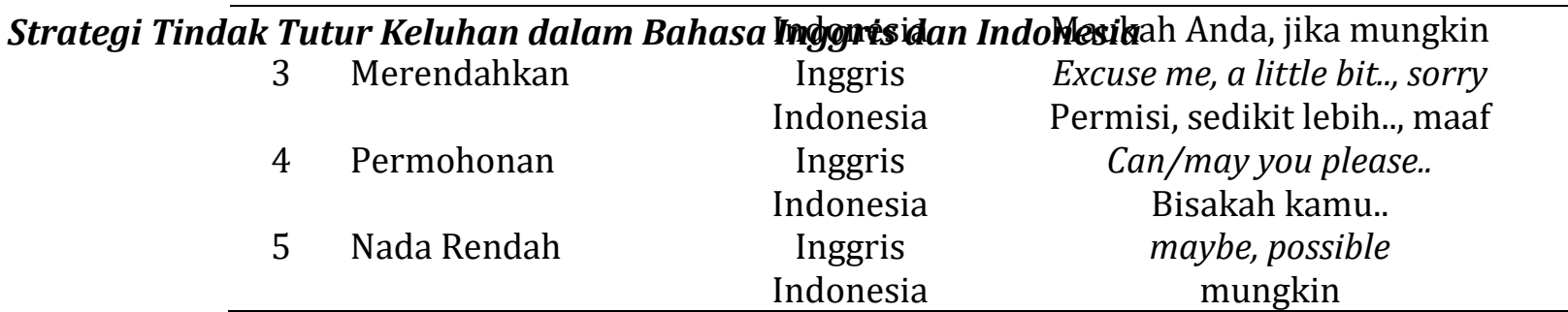

Walaupun menggunakan strategi yang sama, frasa di atas membuat keluhan lebih halus saat diucapkan. Hal ini dapat dilihat pada penggunaan strategi ancaman pada produksi keluhan "Hi! I thought you broke the screen yesterday. Is it possible you replace it soon? I have an exam coming and need to use it" dibandingkan dengan menggunakan tuturan "Dude, you broke my laptop, you're gonna pay for it!" pada respon situasi merusakkan barang pinjaman. Keduanya mengharapkan ganti rugi pada mitra tutur namun dituturkan pada level kesantunan yang berbeda, sehingga akan mendapatkan perbedaan respon mitra tutur. Sedangkan penggunaan penghinaan pada pernyataan "Fuck you, Bitch! Please fix it!" adalah penggunaan strategi ancaman paling gamblang yang diucapkan oleh penutur pada situasi serupa.

Hal yang serupa juga ditunjukkan pada penggunaan keluhan berbahasa Indonesia pada situasi merusakkan barang pribadi. Dibandingkan menggunakan kalimat "Tolong bersihkan!", terdapat responden yang memilih menggunakan tuturan "Bukuku ada sausnya. Bisa dibersihkan dulu?" atau dengan strategi yang berbeda yakni dengan kalimat " Kenapa Ceroboh? Catatanku dulu lebih bersih. Lain waktu jangan diulangi". Hal ini mencerminkan penggunaan keluhan dengan strategi yang sama (ingin pertanggungjawaban) namun dengan frasa merendah yang berbeda.

Pada situasi kegaduhan dalam ranah privasi, penggunaan ekspresi keluhan dengan menggunakan frasa merendah ditunjukkan pada produksi tuturan "Can you please shut your music down?" atau dengan pertanyaan "Hi! I'm in the flat near yours and I can't sleep, may you play a little bit less loudy?" dibandingkan dengan pernyataan responden dengan perintah langsung, "Turn down, please". Sedangkan pada situasi yang sama, responden menggunakan ekspresi dalam bahasa Indonesia seperti, "Hai, aku dekat kamarmu dan dengar suaramu keras. Boleh kamu tidak keras?" atau dengan ekspresi "Bisa kamu turunkan suaranya? Saya ingin tidur."

Hal tersebut senada dengan pernyataan Wolfson (1986: 72) yang menggunakan istilah "bulge" untuk mengidentifikasikan negosiasi untuk diberikan pertanggungjawaban atas keluhannya dan menggunakan tuturan lebih panjang saat berinteraksi dengan orang yang belum dikenal sebelumnya atau dengan orang yang tidak dekat secara jarak sosial. Proses ini bertujuan agar interaksi di masa mendatang dapat berlanjut. Hal ini digambarkan pada situasi kegaduhan pada ranah privasi yang berlangsung pada interaksi tetangga kamar, penutur lebih memilih memperkenalkan diri terlebih dahulu dan menjelaskan kondisinya kepada mitra tutur dibandingan tuturan keluhan langsung dengan menuturkan "Hai, aku dekat kamarmu dan dengar suaramu keras. Boleh kamu tidak keras?" ataupun pada situasi menunggu antrian dengan menjelaskan keadaan pribadinya dengan menuturkan "Wah, aku tunggu sangat lama. Mungkin di masa depan aku bisa mandi pertama?" 
Strategi Tindak Tutur Keluhan dalam Bahasa Inggris dan Indonesia

Tabel 2. Distribusi strategi tindak tutur dengan perbedaan status sosial dan jarak sosial dalam persen

\begin{tabular}{clccc}
\hline No. & \multicolumn{1}{c}{ Strategi } & S (+P) & Equals & S (-P) \\
& & H (-P) & & 50 \\
\hline 1 & Implisit & 0 & 0 & 25 \\
2 & Pertidaksetujuan & 31.25 & 6.25 & 18.25 \\
3 & Eksplisit & 0 & 87.5 & 6.25 \\
4 & Peringatan & 6.25 & 6.25 & 0 \\
5 & Ancaman & 62.5 & 0 &
\end{tabular}

$\mathrm{S}=$ Penutur, $\mathrm{H}=$ Mitra tutur, $\mathrm{P}=$ kuasa (power)

Pada status sosial penutur yang lebih tinggi dari pada mitra tutur, penggunaan ancaman dipilih paling banyak dibanding strategi keluhan yang lain. Ancaman ini digunakan untuk meminta ganti rugi atau pertanggungjawaban atas tindakan mitra tutur atas tanggung jawabnya pada peristiwa tidak nyaman, seperti yang digambarkan pada respon, "Dude, you broke my laptop, you're gonna pay for it!" pada situasi merusakkan barang pinjaman. Namun ketika penutur berhadapan dengan mitra tutur dengan status sosial yang sejajar, pemilihan strategi keluhan beralih pada ujaran eksplisit yang dicirikan penggunaan penunjukan argumen penanggungjawab dengan terang (you atau kamu), seperti pada respon "Can you please shut your music down?" atau dengan ekspresi "Aku ada kelas juga. Boleh kamu cepat?"

Sebaliknya, ketika status mitra tutur lebih tinggi daripada penutur, penggunaan strategi tindak tutur berganti dengan pernyataan implisit. Hal yang menarik dari keluhan penilaian dosen adalah penutur menggunakan pertanyaan yang berkaitan dengan kesalahan diri sang penutur. Hal ini yang kemudian membedakan dengan jelas dengan strategi lainnya walaupun dosen yang diberikan keluhan mempunyai jarak sosial yang berdekatan dengan penutur namun mempunyai status sosial yang lebih tinggi, yang tergambar pada tuturan "Hi! I'm wondering about what was wrong in my task and if it's possible to make a make up exam of an extra work to make it better?" dan tuturan "Masalahnya saya membuat kesalahan di tes. Mengapa saya menerima nilai C?". Tuturan pertama maupun kedua menggunakan frasa merendah dengan menyatakan kesalahan diri untuk mengawali keluhan tentang nilai yang didapat. Berkebalikan dengan status sosial penutur yang lebih tinggi, untuk status sosial setara dan lebih rendah sama sekali tidak menggunakan strategi ancaman.

Tabel 3. Distribusi strategi tindak tutur dengan perbedaan norma sosial dan jarak sosial dalam persen

\begin{tabular}{clcc}
\hline No. & \multicolumn{1}{c}{ Strategi } & $(+\mathrm{I})$ & $(-\mathrm{I})$ \\
\hline 1 & Implisit & 25 & 25 \\
2 & Pertidaksetujuan & 0 & 62.5 \\
3 & Eksplisit & 75 & 12.5 \\
4 & Peringatan & 0 & 0 \\
5 & Ancaman & 0 & 0 \\
\hline
\end{tabular}

$\mathrm{S}=$ Penutur, $\mathrm{H}=$ Mitra tutur, $\mathrm{I}=$ kedekatan (intimacy)

Pada pertanyaan dua terakhir yang berisi tentang sistem sosial di Indonesia yang sering menjadi pemicu keluhan oleh mahasiswa asing. Pada situasi 7 dan 8 yang menggambarkan keterlambatan dan pertanyaan privasi seperti agama, status pernikahan 
dan umur pada awal perkenalan. Strategi yang dipakai pada kedua situasi tersebut adalah menyatakan pertidaksetujuan atau penolakan seperti yang digambarkan pada tuturan " $I$ can tell you, but it's confidential, maybe later." dan tuturan "Saya belum bisa menjawab, teman.". Pada interaksi awal perkenalan, seorang pembelajar bahasa kedua lebih menghindari tuturan yang mengancam muka secara langsung. Penghindaran tersebut digambarkan dengan frasa merendah karena jarak sosial antara penutur dan mitra tutur belum terjalin kedekatan.

Berbeda dengan keterlambatan untuk teman sekelas, penutur lebih memilih tuturan eksplisit dengan "Hi, guys. May you hurry up a little bit, I have a group work to do after this." dan tuturan "Jam karet yah, lebih cepat di masa depan yah. Kita harus lakukan tugas ini." karena jarak sosial antara penutur dan mitra tutur telah berdekatan.

\section{Strategi Tindak Tutur Keluhan pada Penutur Pembelajar Bahasa Kedua}

Salah satu rumusan masalah pada penelitian ini adalah untuk mengidentifikasi transfer pragmatik yang diproduksi oleh pembelajar bahasa Indonesia. Ada dua hipotesis yang diformulasikan berdasarkan penelitian sebelumnya. Berdasarkan penelitian Fatmasari (2015), penutur jati bahasa Indonesia menghindari penggunaan keluhan ancaman langsung dengan penunjukan kesalahan melalui respon Discourse Completion Test.

Tabel 4. Distribusi produksi strategi tindak tutur pada penggunaan bahasa Inggris dan Indonesia dalam persen

\begin{tabular}{clcc}
\hline No. & \multicolumn{1}{c}{ Strategi } & Bahasa Inggris & $\begin{array}{c}\text { Bahasa } \\
\text { Indonesia }\end{array}$ \\
\hline 1 & Implisit & 18.75 & 18.75 \\
2 & Pertidaksetujuan & 28.125 & 21.875 \\
3 & Eksplisit & 34.375 & 34.375 \\
4 & Peringatan & 0 & 12.5 \\
5 & Ancaman & 18.75 & 12.5 \\
\hline
\end{tabular}

Mayoritas responden akan merespon dengan menerjemahkan secara literal ekspresi keluhan dari bahasa Inggris ke bahasa Indonesia. Hal ini ditunjukkan dalam tabel bahwa penutur tidak banyak mengganti strategi walaupun dengan respon bahasa yang berbeda, hal tersebut dapat dipengaruhi oleh faktor lama tinggal di Indonesia pada kisaran kurang dari 6 bulan, yang karenanya mempengaruhi transfer kebahasaan pada tindak tutur keluhan belum diproduksi secara maksimal untuk penerapan faktor kultural di Indonesia. Sehingga dapat disebutkan bahwa produksi tindak tutur melalui keluhan ini masih dalam fenomena transfer negatif. Didukung dengan penelitian Fatmasari (2015) mengungkapkan bahwa penutur jati Indonesia tidak menggunakan bentuk strategi dengan mencela dan menyalahkan mitra tutur walaupun dengan status sosial yang lebih rendah, seperti pernyataan "Kenapa ceroboh" pada situasi pengrusakan barang yang menggambarkan bahwa pembelajar bahasa Indonesia belum menempatkan strategi pragmatik bahasa Indonesia dengan sempurna. 


\section{SIMPULAN}

Pada penutur yang berstatus sosial lebih tinggi dari mitra tutur, penggunaan ancaman paling banyak digunakan untuk responden. Ancaman ini digunakan untuk meminta ganti rugi atau pertanggungjawaban atas tindakan mitra tutur atas tanggung jawabnya pada peristiwa tidak nyaman. Namun ketika penutur berhadapan dengan mitra tutur dengan status sosial yang sejajar, pemilihan strategi keluhan beralih pada ujaran eksplisit yang dicirikan penggunaan kalimat dengan argumen penanggungjawab secara terang (you atau kamu). Sebaliknya, ketika status mitra tutur lebih tinggi daripada penutur, penggunaan strategi tindak tutur berganti dengan pernyataan implisit.

Budaya tepat waktu yang dilanggar dapat memancing keluhan. Pada keterlambatan, penutur lebih memilih tuturan eksplisit karena jarak sosial antara penutur dan mitra tutur telah berdekatan. Namun dalam wacana informasi privasi dan sensitif, semua responden sepakat untuk memberikan penolakan daripada sebuah tindak tutur keluhan.

Transfer kebahasaan pada tindak tutur keluhan belum secara maksimal digunakan dengan adaptasi faktor kultural di Indonesia, sehingga dapat disimpulkan masih terjadi transfer negatif dikarenakan mayoritas responden merespon dengan menerjemahkan secara literal ekspresi keluhan dari bahasa Inggris ke bahasa Indonesia. Hal ini juga dipengaruhi oleh faktor lama tinggal di Indonesia kurang dari 6 bulan.

\section{RUJUKAN}

Blum-Kulka, S. \& Kasper, G. (1993). Interlanguage pragmatics. New York: Oxford University Press.

Canale, M. \& Swain, M. (1980) Theoretical bases of communicative approaches to second language teaching and testing. Applied Linguistics. Vol. 1.1.

Ellis, R. (1994). The study of second language acquisition. UK: Oxford University Press.

Fatmasari, D.R. (2015). Strategi komplain dari pembelajar Bahasa Inggris sebagai Bahasa Asing dalam perspektif tugas penyelesaian percakapan (studi kasus terhadap mahasiswa Sastra Inggris Universitas Brawijaya) (Thesis magister). Universitas Brawijaya.

Hymes, D. (1972). On communicative competence. Dalam Pride, J.B. \& Holmes, J. Sociolinguistics (hal. 269-293). Middlesex: Penguin Books

Kasper, G. (2000). Data collection in pragmatics research. Dalam Spencer-Oatey, H. Culturally Speaking: Managing Rapport through Talk across Cultures, 316-369. London: Continuum.

Leech, G. (1983). Principles of pragmatics. London: Longman.

Mahsun. (2014). Metode penelitian bahasa. Jakarta: Rajawali Press. 
Olshtain, E. \& Weinbach, L. (1993). Interlanguage features of the speech act of complaining. Dalam Blum-Kulka, S. \& Kasper, G., Interlanguage Pragmatics (hal. 108-122). New York: Oxford University Press.

Raymonda, A., Djatmika, Subroto, E. (2016). Analisis sosioragmatik pada fungsi tindak tutur komunitas pemain game online di Kota Solo. Prasasti: Journal of Linguistics, 1(2), 230-248.

Rohmadi, M. (2019). Analisis Psikopragmatik pada Tindak Tutur Meminta Mas Yuma dan Mas Briliant pada Ranah Keluarga Yuma Perkasa. Prasasti: Journal of Linguistics, 4(2), 95-103.

Trosborg, A. (1995). Interlanguage pragmatics: requests, complaints and apologies. Berlin: Mouton de Gruyter.

Vanrell, M., Feldhausen, I. \& Astruc, L., (2018). The Discourse Completion Task in Romance prosody research: Status quo and outlook. Dalam Feldhausen, I., Fliessbach, J. \& Vanrell, M. Methods in prosody: A Romance language perspective, 191-227. Berlin: Language Science Press.

Widayanti, S. R. \& Kustinah. (2019). analisis pragmatik pada fungsi tindak tutur dalam film karya Walt Disney. Prasasti: Journal of Linguistics, 4(2), 180-185.

Widdowson, H. G. (1978). Teaching language as communication. UK: Oxford University Press.

Wolfson, N. (1986). The Bulge: A theory of speech behavior and social. Working Papers in Educational Linguistics (WPEL), 55-83.

Yang, H. (2016). A Cross-cultural Study of Complaint Strategies by Chinese and British University Students. International Conference on Education, 207-211. 